\title{
Water-soluble SNS cationic palladium(II) complexes and their Suzuki-Miyaura cross-coupling reactions in aqueous medium
}

\author{
Alphonse Fiebor ${ }^{1}$, Richard Tia ${ }^{2}$, Banothile C. E. Makhubela ${ }^{* 1}$ and Henok H. Kinfe ${ }^{* 1}$
}

\author{
Full Research Paper \\ Address: \\ ${ }^{1}$ Department of Chemistry, University of Johannesburg, PO Box 524, \\ Auckland Park 2006, South Africa and ${ }^{2}$ Department of Chemistry, \\ Kwame Nkrumah University of Science and Technology, Kumasi, \\ Ghana \\ Email: \\ Banothile C. E. Makhubela* - bmakhubela@uj.ac.za; \\ Henok H. Kinfe* - hhkinfe@uj.ac.za \\ * Corresponding author \\ Keywords: \\ cationic palladium(II) complexes; Pd(II)/Pd(IV) complexes; SNS pincer \\ complexes; Suzuki-Miyaura
}

Beilstein J. Org. Chem. 2018, 14, 1859-1870.

doi:10.3762/bjoc. 14.160

Received: 11 May 2018

Accepted: 26 June 2018

Published: 23 July 2018

Associate Editor: L. Ackermann

(C) 2018 Fiebor et al.; licensee Beilstein-Institut. License and terms: see end of document.

\begin{abstract}
Unlike their SCS analogues, SNS pincer complexes are poorly studied for their use in coupling reactions. Accordingly, a series of water soluble cationic Pd(II) SNS pincer complexes have been successfully synthesised and investigated in detail for their catalytic activity in Suzuki-Miyaura coupling reactions. By using only $0.5 \mathrm{~mol} \%$ loading of the complexes, the coupling of inactivated aryl bromides and activated aryl chlorides with various boronic acids in water was achieved in excellent yields and the catalysts were found to be reusable for three cycles without a significant loss of activity. The investigation of the mechanism of the reaction revealed that a $\mathrm{Pd}(\mathrm{II})$ to $\mathrm{Pd}(\mathrm{IV})$ route is the more likely pathway which was further supported by computational studies.
\end{abstract}

\section{Introduction}

The Suzuki-Miyaura $\mathrm{C}-\mathrm{C}$ coupling reaction is a powerful method for the synthesis of ubiquitous biaryls and has been extensively employed in the synthesis of natural products, pharmaceuticals, agrochemicals, and polymers. The reaction usually involves a palladium-catalysed coupling of aryl boronates with aryl halides in organic solvents in the presence of an excess of base [1-3]. With the drive for the development of environmentally friendly and low cost protocols, a number of methodologies for the Suzuki-Miyaura reaction under aqueous conditions or in neat water have been reported [4-6]. This has been achieved via microwave heating [7-15], ultrasonication [16-18], ligand-free methodologies [19-25] and the use of water-soluble palladium pre-catalysts/catalysts [26-30]. The latter is the preferred choice since it allows for the reusability of the catalyst for subsequent reactions after simple phase separation [31]. However, the commonly employed phosphorous and carbene ligand-based palladium(II) complexes are found to be in most cases sensitive to moisture and air limiting the scope of their catalytic application in aqueous reactions $[32,33]$. This limitation encouraged for the development of organosulfur ligand based palladium(II) complexes by exploiting the strong donor properties of sulfur. Such complexes are found to be resistant 
to moisture, air and thermal stress/elevated temperatures and have been applied in catalysing Suzuki-Miyaura coupling reactions [32,33]. As it was elegantly reviewed by Singh and co-workers [33], these organosulfur ligands can be classified into pincer type (symmetrical and unsymmetrical), thioethers, thiourea-based ligands, sulfur-substituted NHCs, thiosemicarbazones and sulfated Schiff bases. Of the pincer ligands, there are several examples of SCS-based palladium(II) complexes (1-13, Figure 1) which were reported to catalyse the Suzuki-Miyaura coupling reaction but the corresponding easyto-synthesise SNS pincer complexes are well underrepresented [33].
To the best of our knowledge, the only examples reported in the literature are the water-soluble pincer complexes 14, 15 and 16 (Figure 2a). While pincer complex 14 provided moderate (38-68\%) GC yields over $6 \mathrm{~h}$ at $75^{\circ} \mathrm{C}$ using $2 \mathrm{~mol} \%$ catalyst loading with inactivated aryl bromides, pincer complex 15 was found to be incompatible with both activated and inactivated aryl bromides according to the study conducted by Bai and Hor [34]. Similarly, Kumar et al. studied the catalytic activity of pincer complex 16 and reported that the catalyst was compatible with activated aryl bromides to provide reasonable yields over $12 \mathrm{~h}$ at $100{ }^{\circ} \mathrm{C}$ using $2 \mathrm{~mol} \%$ catalyst loading; but required stoichiometric amounts of tetra- $n$-butylammonium bro-

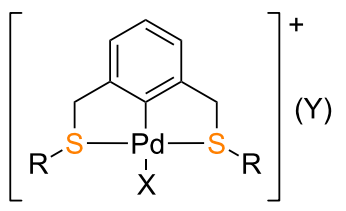

$1 \mathrm{R}=\mathrm{CH}_{3}, \mathrm{X}=\mathrm{Cl}, \mathrm{Y}=\mathrm{OTf}^{-}, \mathrm{Cl}^{-}, \mathrm{BArF}^{-}, \mathrm{SO}_{4}{ }^{2-}$ $2 \mathrm{R}=t-\mathrm{Bu}, \mathrm{X}=\mathrm{Cl}, \mathrm{Y}=\mathrm{OTf}^{-}, \mathrm{Cl}^{-}, \mathrm{BArF}^{-}, \mathrm{SO}_{4}{ }^{2}-$ $3 \mathrm{R}=\mathrm{iPr}, \mathrm{X}=\mathrm{Cl}, \mathrm{Y}=\mathrm{OTf}^{-}, \mathrm{Cl}^{-}, \mathrm{BArF}^{-}, \mathrm{SO}_{4}{ }^{2-}$ $4 \mathrm{R}=t-\mathrm{Bu}, \mathrm{X}=\mathrm{OH}_{2}, \mathrm{Y}=\mathrm{SO}_{4}{ }^{2-}, \mathrm{OTf}^{-}, \mathrm{Cl}^{-}, \mathrm{BArF}^{-}$ $5 \mathrm{R}=\mathrm{iPr}, \mathrm{X}=\mathrm{OH}_{2}, \mathrm{Y}=\mathrm{SO}_{4}{ }^{2-}, \mathrm{OTf}^{-}, \mathrm{Cl}^{-}, \mathrm{BArF}^{-}$

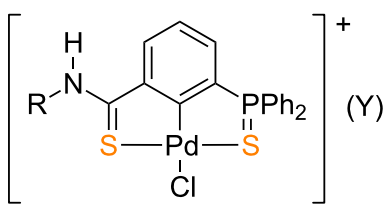

$6 \mathrm{R}=\mathrm{Ph}$,

$$
\mathrm{Y}=\mathrm{OTf}^{-}, \mathrm{Cl}^{-}, \mathrm{BArF}^{-}, \mathrm{SO}_{4}{ }^{2-}
$$

$7 \mathrm{R}=\mathrm{CH}_{2} \mathrm{Ph}$, $\mathrm{Y}=\mathrm{OTf}^{-}, \mathrm{Cl}^{-}, \mathrm{BArF}^{-}, \mathrm{SO}_{4}^{2-}$

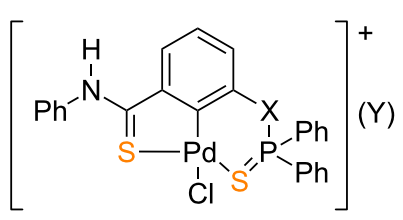

$8 \mathrm{X}=\mathrm{NH}, \mathrm{Y}=\mathrm{OTf}^{-}, \mathrm{Cl}^{-}, \mathrm{BArF}^{-}, \mathrm{SO}_{4}{ }^{2-}$ $9 \mathrm{X}=\mathrm{O}, \mathrm{Y}=\mathrm{OTf}^{-}, \mathrm{Cl}^{-}, \mathrm{BArF}^{-}, \mathrm{SO}_{4}^{2-}$

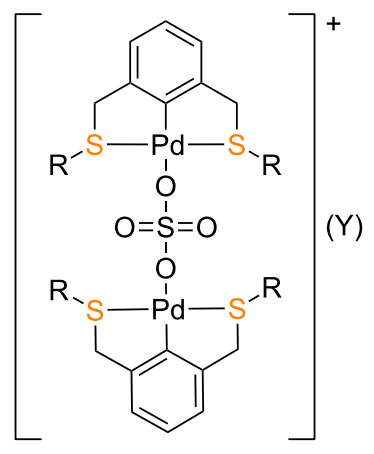

$10 \mathrm{R}=\mathrm{Me}$

$11 \mathrm{R}=t-\mathrm{Bu}$

$\mathrm{Y}=\mathrm{PF}_{6}, \mathrm{BF}_{4}, \mathrm{OTf}^{-}, \mathrm{Cl}^{-}, \mathrm{BArF}^{-}, \mathrm{SO}_{4}{ }^{2-}$

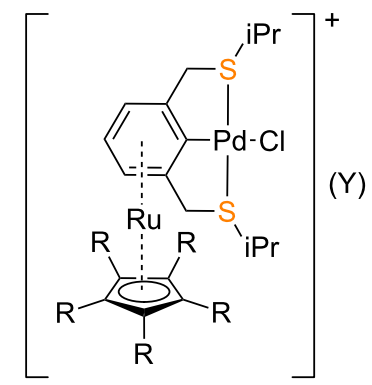

$12 \mathrm{R}=\mathrm{H}, \mathrm{Y}=\mathrm{PF}_{6}, \mathrm{OTf}^{-}, \mathrm{Cl}^{-}, \mathrm{BArF}^{-}, \mathrm{SO}_{4}{ }^{2-}$ $13 \mathrm{R}=\mathrm{Me}, \mathrm{Y}=\mathrm{BF}_{4}, \mathrm{OTf}^{-}, \mathrm{Cl}^{-}, \mathrm{BArF}^{-}, \mathrm{SO}_{4}{ }^{2-}$

Figure 1: Examples of reported SCS palladium(II) pincer complexes 1-13.

a)

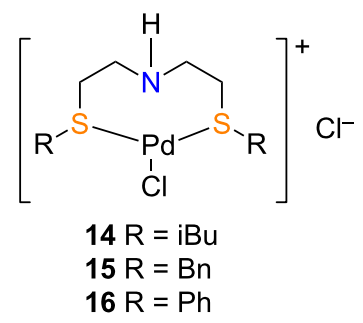

b)

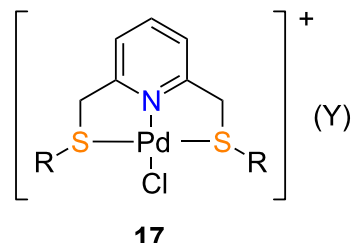

17

$\mathrm{Y}=\mathrm{OTf}^{-}, \mathrm{Cl}^{-}$ 
mide (TBAB) to effect the reaction of inactivated aryl bromides [35]. A further limitation of these catalysts is their incapability to catalyse the coupling reaction when either activated or inactivated aryl chlorides are employed as coupling partners. Encouraged by the high hydrophilicity and the potential activity of such complexes, we are interested in the synthesis of cationic palladium(II) SNS pincer complexes of the general structure 17 (Figure 2b) having rigid fused cyclic rings imparted by a pyridine backbone; and systematic investigation of their catalytic activity in the aqueous Suzuki-Miyaura coupling reaction. Herein, we report the synthesis of the SNS Pd(II) pincer complexes and their interesting catalytic activities in the Suzuki-Miyaura cross coupling reactions in neat water.

\section{Results and Discussion}

Our study commenced with the preparation of the SNS pincer ligand 19a using literature reported protocols [36] as shown in Scheme 1. Treatment of in situ-generated thiophenolate with 2,6-bis(chloromethyl)pyridine (18) afforded pincer ligand 19a in $73 \%$ yield. Initial attempts for the synthesis of SNS-Pd(II) complex 17a (with $\mathrm{Cl}^{-}$counter ion) were unsuccessful since the reaction of the SNS pincer ligand 19a with $\mathrm{PdCl}_{2}(\mathrm{MeCN})_{2}$ led to the formation of N,S-Pd(II) 20a presumably due to the weak basicity of the sulfur atom. Gratifyingly, the problem was solved by treatment of the reaction mixture with the halide abstractor AgOTf to provide the desired SNS-Pd(II) complex 17a in quantitative yield (Scheme 1).

The structure of the complex was established using NMR spectroscopy and high-resolution mass spectrometry. Among others, the downfield shift of all the protons in the complex, when compared to the corresponding protons of the ligand, by a difference of $\Delta \delta_{\mathrm{H}} 0.5$ to 1.3 suggests the deshielding of the nuclei due to coordination with the palladium. The downfield shift of the protons is in accordance with other previously reported palladium(II) complexes [37]. The symmetry of the complex was supported by the appearance of the two protons of the pyridine moiety as a doublet at $\delta_{\mathrm{H}}$ 7.76. Furthermore, the formation of the two fused five-membered rings was confirmed by the appearance of the axial and equatorial protons of the bridging methylene groups as two broad singlets at $\delta_{\mathrm{H}} 5.59$ and $\delta_{\mathrm{H}} 5.16$ each integrating for two protons as opposed to the appearance of the corresponding protons in the ligand as a singlet at $\delta_{\mathrm{H}} 4.29$ integrating for four protons. In a similar fashion, complex $\mathbf{1 7} \mathbf{b}$ was synthesised and characterised successfully while ligands 19c and 19d possessing the electron-donating thioether side groups favoured the formation of the corresponding pincer complexes $17 \mathbf{c}$ and $\mathbf{1 7 d}$ directly without formation of an isolable bidentate intermediate observed during the synthesis of complexes 17a and 17b. Furthermore, the successful synthesis of the pincer complexes was confirmed by X-ray crystallography and the representative X-ray crystal structure of $\mathbf{1 7} \mathbf{d}$ is shown in Figure 3 [38].

Single crystals suitable for X-ray analysis of complexes $\mathbf{1 7 d}$ were obtained by slow evaporation of a mixture of dichloromethane and diethyl ether at about $-4{ }^{\circ} \mathrm{C}$. Crystallographic data and structure refinement parameters for $\mathbf{1 7} \mathbf{d}$ are summarised in Table 1. Formation of the tridentate pincer complex was confirmed by the crystal structure of $\mathbf{1 7 d}$. The structure is

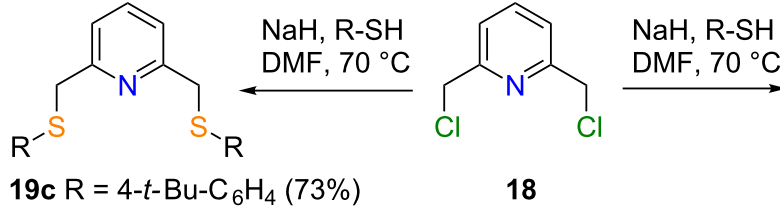

19d $R=s-B u(87 \%)$

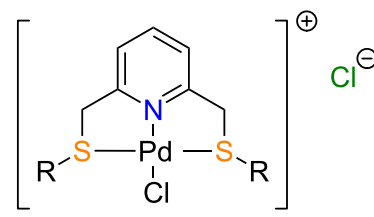

$17 \mathrm{c} \mathrm{R}=4-\mathrm{t}-\mathrm{Bu}-\mathrm{C}_{6} \mathrm{H}_{4}(82 \%)$ $17 \mathrm{~d} R=s-\mathrm{Bu}(70 \%)$

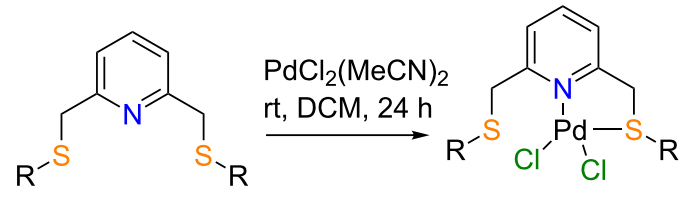

19a $\mathrm{R}=\mathrm{Ph}(73 \%)$ 20a $\mathrm{R}=\mathrm{Ph}$ 19b $\mathrm{R}=p-\mathrm{Br}-\mathrm{C}_{6} \mathrm{H}_{4}(57 \%)$ 20b R $=p-\mathrm{Br}-\mathrm{C}_{6} \mathrm{H}_{4}$ $\mathrm{PdCl}_{2}(\mathrm{MeCN})_{2}$ rt, $\mathrm{MeOH}, 24 \mathrm{~h}$<smiles></smiles>

17a $\mathrm{R}=\mathrm{Ph}(84 \%)$ 17b $\mathrm{R}=p-\mathrm{Br}-\mathrm{C}_{6} \mathrm{H}_{4}(89 \%)$ 


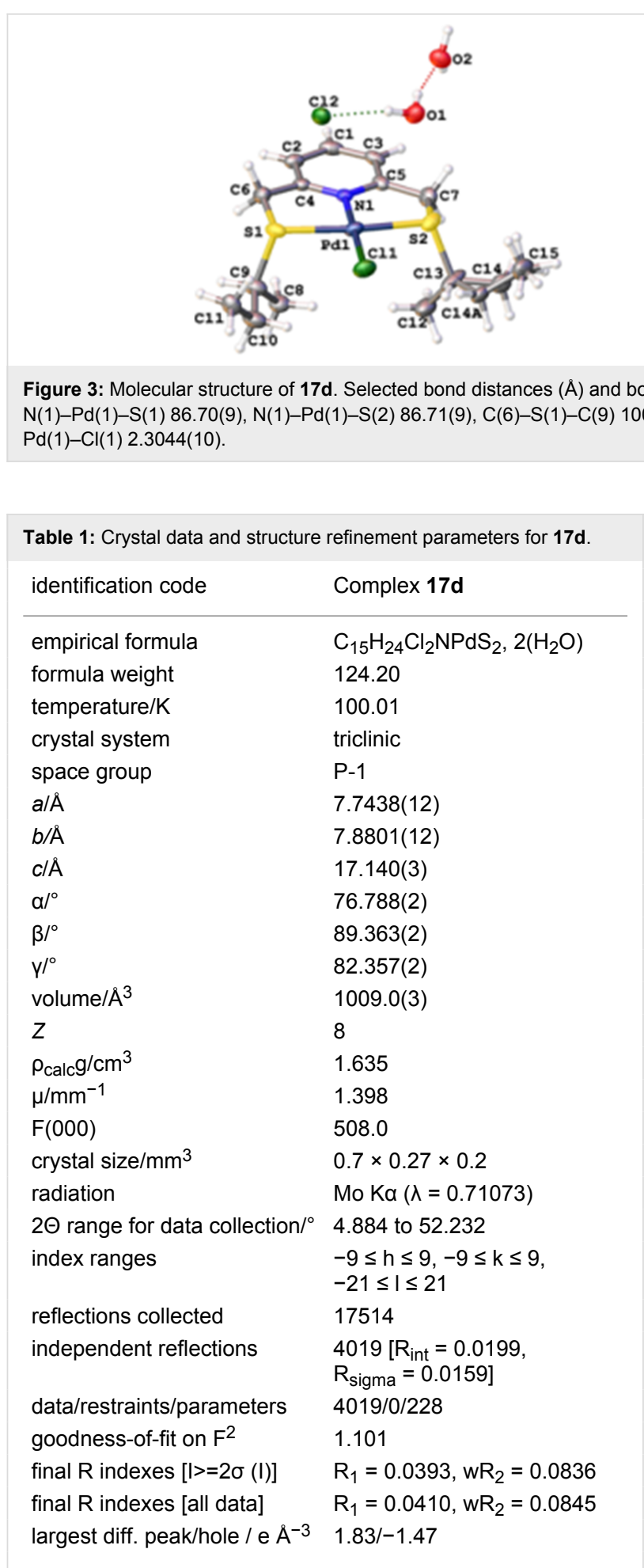

accompanied by two lattice water molecules interacting with each other and an uncoordinated chloride ion through hydrogen bonding. The expected square planar geometry of palladium(II) complexes can be observed in the crystal structure of $17 \mathbf{d}$ where the bond angles around the palladium metal centre are $93.27(4)^{\circ}, 93.34(4)^{\circ}, 86.70(9)^{\circ}$ and $86.71(9)^{\circ}$ for
$\mathrm{S}(1)-\mathrm{Pd}(1)-\mathrm{Cl}(1), \mathrm{S}(2)-\mathrm{Pd}(1)-\mathrm{Cl}(1), \mathrm{N}(1)-\mathrm{Pd}(1)-\mathrm{S}(1)$ and $\mathrm{N}(1)-\mathrm{Pd}(1)-\mathrm{S}(2)$, respectively. It is observed that the sec-butyl groups attached to the sulfur atom are pointing away from the plane of the metal centre such that the thioether angles are $100.2(2)^{\circ}$ and $102.72(2)^{\circ}$ corresponding to $\mathrm{C}(6)-\mathrm{S}(1)-\mathrm{C}(9)$ and $\mathrm{C}(7)-\mathrm{S}(2)-\mathrm{C}(13)$, respectively. The thioether $\mathrm{C}-\mathrm{S}$ bond lengths obtained are 1.808(4) $\AA$ and 1.816(4) $\AA$ for $\mathrm{S}(1)-\mathrm{C}(6)$ and $\mathrm{S}(2)-\mathrm{C}(7)$, respectively.

The thioether bond lengths and angles were found to be consistent to the reported data of $1.816 \AA$ and $100.75^{\circ}$, respectively, by Sogukomerogullari et al. [39]. Similarly, the $\mathrm{Pd}-\mathrm{Cl}$ bond length of 17d (2.3044(10) $\AA$ ) also corresponds to that of square planar complexes with a chlorine ligand reported in literature [40]. The crystal structure of $\mathbf{1 7} \mathbf{d}$ also shows a static disorder of a $\mathrm{CH}_{2}$ carbon of one of the sec-butyl groups (C14). The atom site occupancy factors of the two positions of the $\mathrm{CH}_{2}$ carbon atom was refined to $0.571(11)$ and $0.429(11)$. This shows that the carbon atom has equal probability of being oriented in the two positions.

With the desired pincer complexes in hand, we then moved on to investigate their potential as catalysts for Suzuki-Miyaura coupling reactions. In our first attempt, the electronically deactivated 4-bromoanisole (21a) along with phenylboronic acid (22a) as coupling partner and pincer complex $17 \mathbf{a}$ as catalyst were selected, in order to identify the optimum catalyst and reaction conditions (Table 2). Carrying out the reaction with equimolar amounts of the coupling partners in water at $140{ }^{\circ} \mathrm{C}$ for 4 hours in the presence of $1 \mathrm{~mol} \%$ pincer complex 17a and $\mathrm{K}_{3} \mathrm{PO}_{4}$ (2 equiv) led to the formation of the biaryl 23a in $92 \%$ yield (Table 2 , entry 1 ). The colour of the reaction mixture remained yellow. The use of solvents other than water gave inferior yields (Table 2, entries 2 and 3) which could be attributed to the high hydrophilicity of the pincer complex $\mathbf{1 7 a}$. Several bases including pyridine, $\mathrm{Et}_{3} \mathrm{~N}, \mathrm{KOH}, \mathrm{K}_{2} \mathrm{CO}_{3}$ and $\mathrm{Cs}_{2} \mathrm{CO}_{3}$ were then evaluated. All except $\mathrm{Et}_{3} \mathrm{~N}$ provided the ex- 
Table 2: Optimization of the Suzuki-Miyaura cross coupling reaction of 4-bromoanisole (21a) and phenylboronic acid (22a).

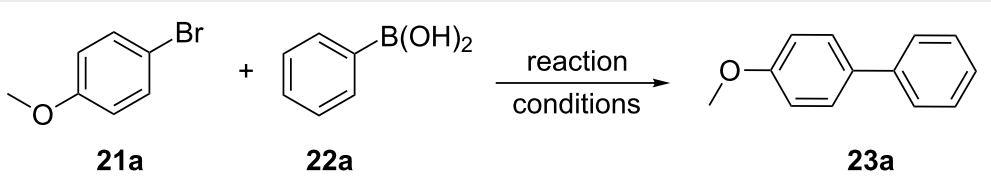

\begin{tabular}{|c|c|c|c|c|c|c|c|c|}
\hline Entry & Base & Solvent & Cat. & Cat. loading & Temp. & Additive & Time (h) & Yield $(\%)^{a}$ \\
\hline 1 & $\mathrm{~K}_{3} \mathrm{PO}_{4}$ & $\mathrm{H}_{2} \mathrm{O}$ & $17 a$ & 1 & 140 & - & 4 & 92 \\
\hline 2 & $\mathrm{~K}_{3} \mathrm{PO}_{4}$ & DMF & $17 a$ & 1 & 140 & - & 4 & 67 \\
\hline 3 & $\mathrm{~K}_{3} \mathrm{PO}_{4}$ & toluene & $17 a$ & 1 & 140 & - & 4 & 0 \\
\hline 4 & Pyr & $\mathrm{H}_{2} \mathrm{O}$ & $17 a$ & 1 & 140 & - & 4 & 90 \\
\hline 5 & $\mathrm{Et}_{3} \mathrm{~N}$ & $\mathrm{H}_{2} \mathrm{O}$ & $17 a$ & 1 & 140 & - & 4 & 51 \\
\hline 6 & $\mathrm{KOH}$ & $\mathrm{H}_{2} \mathrm{O}$ & $17 a$ & 1 & 140 & - & 4 & 90 \\
\hline 7 & $\mathrm{~K}_{2} \mathrm{CO}_{3}$ & $\mathrm{H}_{2} \mathrm{O}$ & $17 a$ & 1 & 140 & - & 4 & 95 \\
\hline 8 & $\mathrm{Cs}_{2} \mathrm{CO}_{3}$ & $\mathrm{H}_{2} \mathrm{O}$ & $17 a$ & 1 & 140 & - & 4 & 92 \\
\hline 9 & $\mathrm{KOH}$ & $\mathrm{H}_{2} \mathrm{O}$ & $17 a$ & 1 & 120 & - & 4 & 93 \\
\hline 10 & $\mathrm{KOH}$ & $\mathrm{H}_{2} \mathrm{O}$ & $17 a$ & 1 & 100 & - & 4 & 84 \\
\hline 11 & $\mathrm{KOH}$ & $\mathrm{H}_{2} \mathrm{O}$ & $17 a$ & 1 & 80 & - & 4 & 79 \\
\hline 12 & $\mathrm{KOH}$ & $\mathrm{H}_{2} \mathrm{O}$ & $17 a$ & 1 & $20(\mathrm{rt})$ & - & 4 & 41 \\
\hline 13 & $\mathrm{KOH}$ & $\mathrm{H}_{2} \mathrm{O}$ & $17 a$ & 1 & 120 & - & 0.5 & 77 \\
\hline 14 & $\mathrm{KOH}$ & $\mathrm{H}_{2} \mathrm{O}$ & $17 a$ & 1 & 120 & - & 1 & 80 \\
\hline 15 & $\mathrm{KOH}$ & $\mathrm{H}_{2} \mathrm{O}$ & $17 a$ & 1 & 120 & - & 2 & 82 \\
\hline 16 & $\mathrm{KOH}$ & $\mathrm{H}_{2} \mathrm{O}$ & $17 a$ & 0.5 & 120 & - & 4 & 86 \\
\hline 17 & $\mathrm{KOH}$ & $\mathrm{H}_{2} \mathrm{O}$ & $17 a$ & 0.25 & 120 & - & 4 & 46 \\
\hline 18 & $\mathrm{KOH}$ & $\mathrm{H}_{2} \mathrm{O}$ & $17 a$ & 0.06 & 120 & - & 4 & 0 \\
\hline 19 & $\mathrm{KOH}$ & $\mathrm{H}_{2} \mathrm{O}$ & $17 a$ & 1 & 120 & TBAB & 1 & 91 \\
\hline 20 & $\mathrm{KOH}$ & $\mathrm{H}_{2} \mathrm{O}$ & $17 a$ & 0.5 & 120 & TBAB & 4 & 94 \\
\hline 21 & $\mathrm{KOH}$ & $\mathrm{H}_{2} \mathrm{O}$ & $17 a$ & 0.5 & 120 & - & 2 & 80 \\
\hline 22 & $\mathrm{KOH}$ & $\mathrm{H}_{2} \mathrm{O}$ & $17 a$ & 0.5 & 120 & TBAB & 2 & 85 \\
\hline 23 & $\mathrm{KOH}$ & $\mathrm{H}_{2} \mathrm{O}$ & $17 c$ & 0.5 & 120 & - & 2 & 73 \\
\hline 24 & $\mathrm{KOH}$ & $\mathrm{H}_{2} \mathrm{O}$ & $17 c$ & 0.5 & 120 & TBAB & 2 & 90 \\
\hline 25 & $\mathrm{KOH}$ & $\mathrm{H}_{2} \mathrm{O}$ & $17 d$ & 0.5 & 120 & - & 2 & 72 \\
\hline 26 & КOH & $\mathrm{H}_{2} \mathrm{O}$ & $17 d$ & 0.5 & 120 & TBAB & 2 & 93 \\
\hline 27 & $\mathrm{KOH}$ & $\mathrm{H}_{2} \mathrm{O}$ & $17 b$ & 0.5 & 120 & - & 2 & 75 \\
\hline 28 & $\mathrm{KOH}$ & $\mathrm{H}_{2} \mathrm{O}$ & $17 b$ & 0.5 & 120 & TBAB & 2 & 85 \\
\hline 29 & $\mathrm{KOH}$ & $\mathrm{H}_{2} \mathrm{O}$ and $\mathrm{Hg}$ & $17 a$ & 0.5 & 120 & & 2 & 72 \\
\hline 30 & $\mathrm{KOH}$ & $\mathrm{H}_{2} \mathrm{O}$ and $\mathrm{Hg}$ & $17 a$ & 0.5 & 120 & TBAB & 2 & 92 \\
\hline
\end{tabular}

${ }^{a} \mathrm{GC}$ yield.

pected biaryl 23a in comparable and excellent yields (Table 2, entries 4-8). The poor performance of $\mathrm{Et}_{3} \mathrm{~N}$ as base in the reaction could be due to its low water solubility. $\mathrm{KOH}$ as a common laboratory reagent gave a comparable yield to the other bases. Therefore, we opted to use $\mathrm{KOH}$ as our preferred base for the reaction. An improved $93 \%$ yield was obtained when the reaction was carried out at $120{ }^{\circ} \mathrm{C}$ (Table 2, entry 9). However, lowering the reaction temperature to less than $120^{\circ} \mathrm{C}$ resulted in comparatively poorer yields (Table 2, entries 10-12). Monitoring of the reaction at different time intervals under otherwise identical conditions showed slightly progressive increase in the yield of the product formed (Table 2, entries 13-15) with a maximum yield of $93 \%$ after 4 hours (Table 2, entry 9 ). Howev- er, stirring the reaction mixture beyond 4 hours did not lead to improved yields. Investigation on the loading of the catalyst indicated that $1 \mathrm{~mol} \%$ was sufficient to drive the reaction to near completion (93\% yield, Table 2, entry 9) considering the minor byproduct formed via homocoupling of the phenylboronic acid coupling partner. Reducing the catalyst loading by half yielded a competitive yield of $86 \%$ (a $7 \%$ decreased yield, Table 2 , entry 16). Catalyst loading of less than $0.5 \mathrm{~mol} \%$ provided inferior yields (Table 2, entries 17 and 18). In agreement with a literature report [27], the addition of TBAB ( 0.5 equiv) improved the performance of the reaction (Table 2, entries 14 vs 19 and 16 vs 20) but the colour of the reaction mixture turned black. 
Among the set of SNS pincer complexes investigated in this study, pincer complex 17a was found to be the most active catalyst in the absence of TBAB as an additive (Table 2, entry 21 vs 23,25 and 27). Such an outcome suggests that the sterically less demanding planar phenyl group renders greater access to the metal centre for the substrates than the bulkier side groups (both with electron-donating and electron-withdrawing substituents) and leads to the enhanced catalytic activity observed for $\mathbf{1 7 a}$, which thus implies that the catalytic activity is influenced by steric as opposed to electronic effects. On the contrary, carrying out the reactions under otherwise identical conditions but with the presence of $\mathrm{TBAB}$, the activity of the catalysts was reversed. The electron rich and sterically demanding tertbutylphenyl and isobutyl thioether possessing SNS pincer complexes resulted in higher yields (Table 2, entry 24 and 26) than the electronically poor and sterically less demanding phenyl group (Table 2, entry 22) as well as the electronically poor but sterically demanding 4-bromophenyl thioether (Table 1, entry 28) possessing SNS pincer complexes. These results suggest that in the presence of TBAB the mechanism of the reaction changes and the catalytic activity seems to be under the influence of electronic as opposed to steric effects. When the reaction mixture turned black in the presence of $\mathrm{TBAB}$, we were under the impression that the reaction could have proceeded via formation of palladium nanoparticles as it is common with most palladium catalysed coupling reactions. However, mercury drop experiments provided comparable yields (Table 2, entry 29 and 30 ) under the same reaction conditions ruling out the possibility of a coupling reaction catalysed by palladium nanoparticles [37].

The fact that the reaction mixture remained yellowish in the absence of TBAB and the mercury drop experiments did not lead to an appreciable decrease in yield, the reaction was proposed to proceed via a $\mathrm{Pd}(\mathrm{II})$ to $\mathrm{Pd}(\mathrm{IV})$ mechanism contrary to the previously reported SNS pincer $\mathrm{Pd}(\mathrm{II})$ complexes which proceeded via formation of Pd nanoparticles [35] (Pd(II) to $\operatorname{Pd}(0)$ type of mechanism). Literature suggestions on a $\mathrm{Pd}(\mathrm{II})$ to $\mathrm{Pd}(\mathrm{IV})$ mechanism are known for biscarbene (CNC), alkylphosphine (PCP) and aminophosphine (PCP) pincer complexes, and in each of these cases, catalysis was unaffected by metallic mercury during the cross-coupling reactions [41-43]. In addition, stable Pd(IV) complexes have been widely prepared and characterised, thus for the catalysis of the pincer complexes in the current study, the $\mathrm{Pd}(\mathrm{II})$ to $\mathrm{Pd}(\mathrm{IV})$ mechanism was proposed as shown in Scheme 2 [44].

In order to verify the viability of the Pd(II) to Pd(IV) mechanism proposed, an exploratory computational study using the semi-empirical PM3 method was performed on the oxidative addition stage of the mechanism to determine if the results ob- tained theoretically could support the experimental results. The oxidative addition stage was selected because it is also the ratedetermining step for the catalytic cycle, and thus it can be used to compare the rate of conversions. The PM3 method has been parameterised for transition metal systems and has been found to give geometries, relative energies and activation energy trends in good agreement with high-level density functional theory (DFT) results at a fraction of the computational cost $[45,46]$. It is therefore adequate for studies in which the prime purpose is to determine or verify preferred reaction pathways.

Oxidative addition of 4-bromoanisole to complex $17 \mathbf{d}$ proceeds by the $\mathrm{C}-\mathrm{Br}$ bond activation to form a weakened $\mathrm{Pd} \cdots \mathrm{Br}$ bond, of $3.104 \AA$ length in transition state (TS1), which ultimately results in a new $\mathrm{Pd}-\mathrm{Br}$ bond, of $2.605 \AA$ length (IM1) (Figure 4). The $\mathrm{Pd}-\mathrm{Br}$ distance is calculated to be $2.60 \AA$ and is consistent with similar $\mathrm{Pd}-\mathrm{Br}$ bond lengths found in the literature for single crystal X-ray structures $[47,48]$. This oxidative addition step involves a low activation energy barrier of $-43.9 \mathrm{kcal} / \mathrm{mol}$. This negative energy implies that there is a stable intermediate between the reactants and the transition state (TS1). Thus, when the energy of the transition state is lower than the energy of the reactants or intermediates from which the transition state is formed it means there is a stable intermediate between them.

Nonetheless, such a relatively low energy barrier indicates that the reaction proceeds at a fast rate in getting to the intermediate (IM1), thus it is kinetically favoured. The reaction then proceeds via transition state TS2, leading to the cleavage of the $\mathrm{C}\left(\mathrm{sp}^{2}\right)-\mathrm{Br}$ bond and the formation of a new $\mathrm{Pd}-\mathrm{C}\left(\mathrm{sp}^{2}\right)$ bond, to form a cis intermediate of energy $-93.0 \mathrm{kcal} / \mathrm{mol}$. The new $\mathrm{Pd}-\mathrm{C}\left(\mathrm{sp}^{2}\right)$ bond distance of $2.00 \AA$ falls within the reported $\mathrm{Pd}-\mathrm{C}\left(\mathrm{sp}^{2}\right)$ bond distances $[47,48]$. Since the bromo ligand is larger in atomic radius than the chloro ligands the more stable form of the oxidative addition product is the trans form. As such, the cis product can isomerise to a more stable trans intermediate of energy $-93.6 \mathrm{kcal} / \mathrm{mol}$ having a $\mathrm{Pd}-\mathrm{C}\left(\mathrm{sp}^{2}\right)$ bond length of $1.99 \AA$.

Next, under the optimal conditions with $\mathbf{1 7} \mathbf{d}$ as a catalyst (since it provided the highest yield in the presence of TBAB, Table 2, entry 26), we examined the substrate scope with different substituents on the aromatic rings of the bromobenzene and phenylboronic acid. The results are summarised in Table 3 and the scope and yields compare favourably well with reported methods. First, the substrate scope of the phenylboronic acid coupling partner was investigated. Under the optimised reaction conditions, the presence of electron-donating and moderately deactivating groups provided slightly better yields and faster reactions than those possessing strongly deactivating sub- 

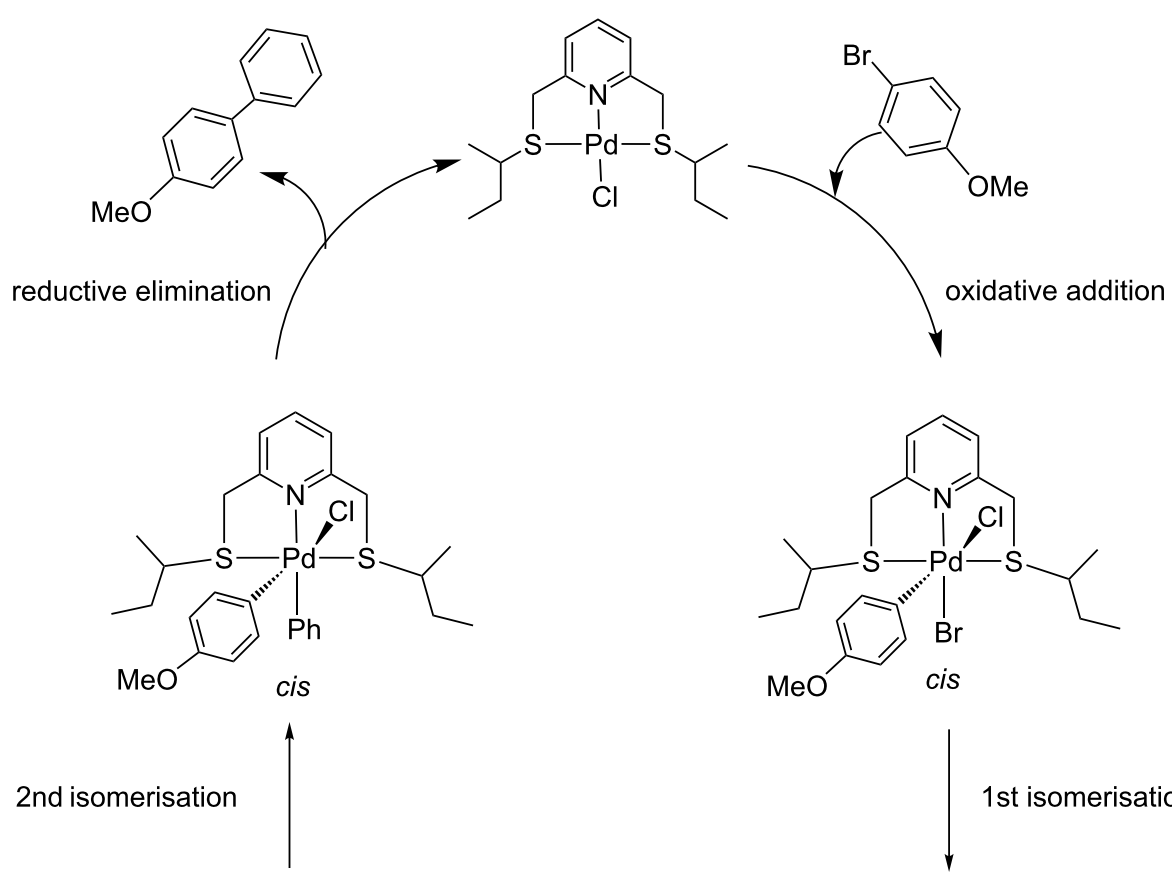

1 st isomerisation

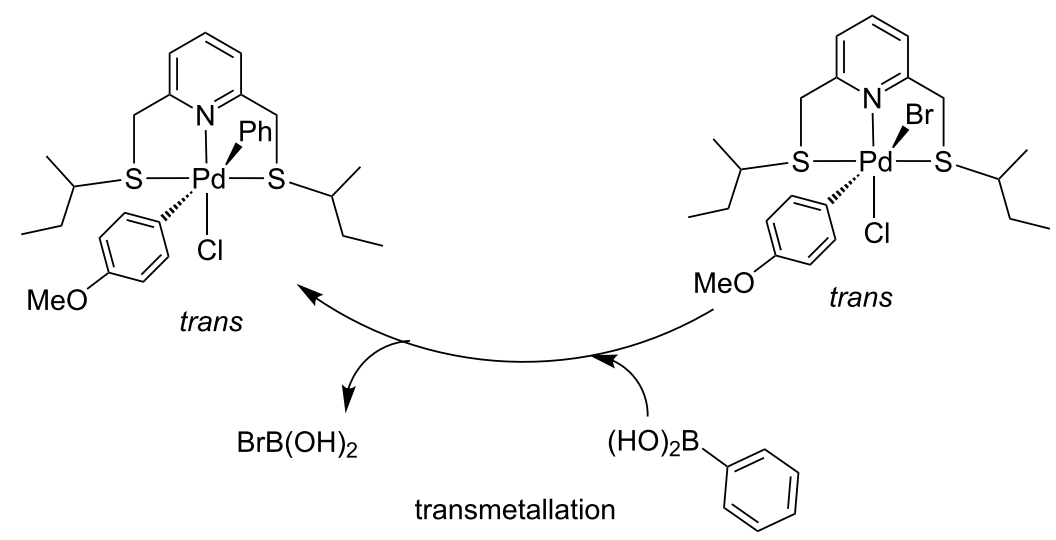

Scheme 2: Proposed mechanism of the Suzuki-Miyaura coupling reaction using pincer complex 17d.

stituents (Table 3, entries 2-4 vs 5). Next, the substrate scope of the aryl bromides was studied. Interestingly, the reaction provided excellent yields with both activated and deactivated aryl bromides, though the presence of a strongly electron-withdrawing substituent gave marginally better yields than those possessing electron-donating groups (Table 3, entries 6-11) without much influence on the rate of the reaction. The slightly lower yield of the reaction in the preparation of $\mathbf{2 3 i}$ could be ascribed to steric encumbrance exerted by the $\mathrm{NO}_{2}$-substituent located at the ortho-position of the aryl bromide.

Encouraged by these results, the reactivities of aryl chlorides were investigated under the optimised conditions. While activated aryl chloride 21 reacted with boronic acids possessing either electron-donating or electron-withdrawing groups to provide the corresponding biaryls in reasonable yields, to our dismay the reaction of inactivated aryl chlorides led to the recovery of starting materials (Table 3 , entries 12 and 13).

Finally, the investigation of the reusability of the catalyst was carried out using the model cross-coupling reaction of 4-bromoanisole (21a) and phenylboronic acid (22a) under the optimised conditions (Scheme 3 and Figure 5). After completion of the reaction, the products were extracted with toluene and to the remaining aqueous layer, which contains the catalyst system, fresh 4-bromoanisole (21a) and phenylboronic acid (22a) were added for the second and third cycles of the reaction. To our delight, the catalyst could be reused at least three times without significant loss of activity $(93 \%, 80 \%$ and $75 \%$ for the 1 st, 2nd and 3rd run, respectively) considering the fact that 


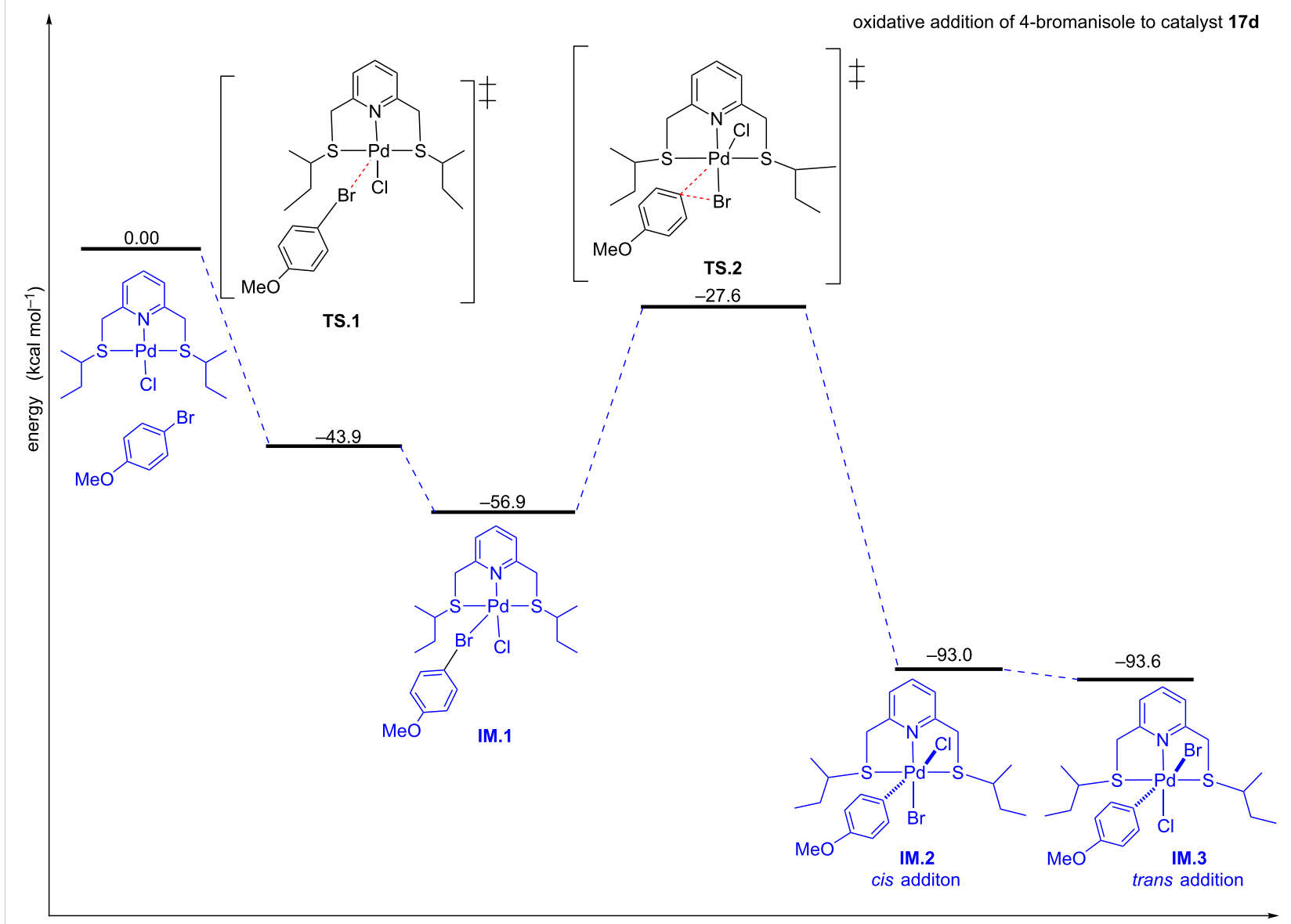

reaction coordinate

Figure 4: Energy profile for the oxidative addition reaction involving 4-bromoanisole and Pd(II) catalyst precursor $17 \mathrm{~d}$. The change in energy for $\mathbf{1 7 d}$ was calculated by computing it in $\mathrm{kcal} / \mathrm{mol}$ as a cation at $298.15 \mathrm{~K}$ and $1 \mathrm{~atm}$.

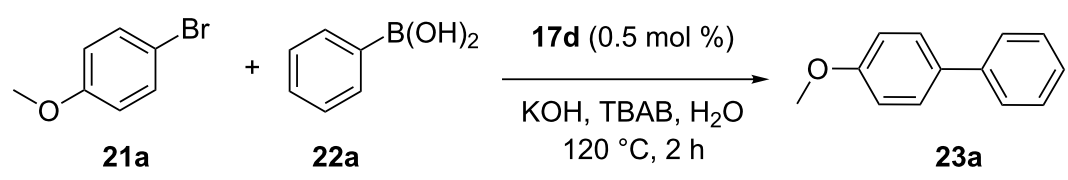

Scheme 3: Investigation on the reusability of the catalyst.

some of it could have been extracted along with the product and the results are summarised in Figure 5.

Since the bidentate complexes $20 \mathrm{a}$ and $\mathbf{2 0 b}$ are also potential catalysts in their own right, the catalytic activity of 20a was investigated in the Suzuki-Miyaura coupling reaction of 4-bromoanisole (21a) and phenylboronic acid (22a) as a proof of concept. As expected, it catalysed the reaction and provided biaryl 23a in moderate yield demonstrating the potential of such complexes in coupling reactions (Scheme 4).

\section{Conclusion}

A series of novel cationic Pd(II) complexes have been successfully synthesised using easy to prepare SNS pincer ligands. A detailed investigation into the application of these complexes in the Suzuki-Miyaura coupling reaction was conducted using various aryl bromides and boronic acids as coupling partners in aqueous medium. All the complexes could catalyse the Suzuki-Miyaura coupling reaction to provide the corresponding biaryls in excellent yields with only $0.5 \mathrm{~mol} \%$ catalyst loading. Furthermore, unlike the previously reported SNS 


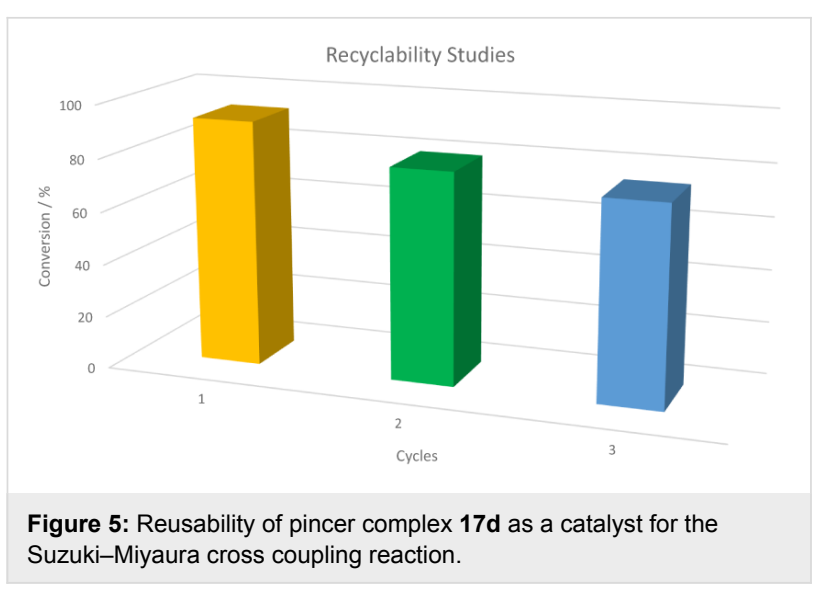

pincer Pd(II) complexes, the catalysts in the current study were compatible with both electron-donating and electron-withdrawing substituents on the aryl bromides and boronic acid substrates as well as activated aryl chlorides. Depending on the presence or absence of the TBAB additive, the reaction may be fine-tuned to either proceed via steric or electronic control. The advantage of using these water-soluble catalysts for the coupling reaction was their reusability for up to three times without significant loss in activity. Moreover, the mechanism of the coupling reaction was probed by a theoretical study that supported the experimental results. Contrary to the previously reported SNS pincer $\mathrm{Pd}(\mathrm{II})$ complexes that were proposed to proceed via a $\operatorname{Pd}(\mathrm{II})$ to $\mathrm{Pd}(0)$ type of mechanism, on the basis of

Table 3: Results from the Suzuki-Miyaura cross-coupling reactions of various aryl bromides and boronic acids using pincer complex $17 \mathbf{d}$ as catalyst. ${ }^{\text {a }}$<smiles>[R][X]c1cccc([X])c1</smiles>

21<smiles>[R][R]1cccc([Hg]O)c1</smiles>

22

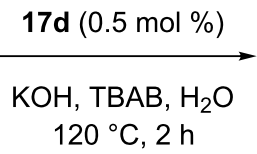

$120^{\circ} \mathrm{C}, 2 \mathrm{~h}$

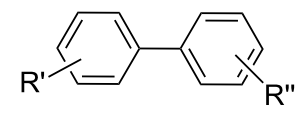

23

Entry

2<smiles>COc1ccc(Br)cc1</smiles>

3

$$
\text { 21a }
$$

OMe<smiles>Cc1ccc(Br)cc1</smiles>

21a

4<smiles>COc1ccc(Br)cc1</smiles>

21a

5<smiles>Oc1ccc(Cl)cc1</smiles>

22b<smiles>COc1cc(Br)cc(OC)c1</smiles><smiles>O=Cc1ccc(Br)cc1</smiles>

22d<smiles>O=[N+]([O-])c1cccc(Br)c1</smiles>

$22 e$<smiles>COc1ccc(-c2cc(OC)cc(OC)c2)cc1</smiles>

94

86

2<smiles>COc1ccc(-c2ccc(C=O)cc2)cc1</smiles>

23d

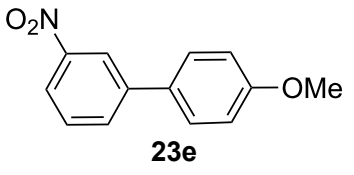

92

86

2

87

81 
Table 3: Results from the Suzuki-Miyaura cross-coupling reactions of various aryl bromides and boronic acids using pincer complex $17 \mathbf{d}$ as catalyst. ${ }^{\text {a }}$ (continued)

6<smiles>CC(=O)c1ccc(Br)cc1</smiles>

7

$$
\text { 21b }
$$<smiles>Nc1ccc(Br)cc1</smiles>

21c

8<smiles>Cc1ccc(Br)cc1</smiles>

9<smiles>COc1ccc(Br)c([N+](=O)[O-])c1</smiles>

10

$21 e$<smiles>COc1ccc(Br)cc1</smiles>

21a

11<smiles>COc1ccc(Br)cc1</smiles>

21a

12<smiles>N#Cc1ccccc1Cl</smiles>

$21 f$

13<smiles>N#Cc1ccccc1Cl</smiles><smiles>COc1ccccc1</smiles>

$22 a$<smiles>COc1ccccc1</smiles>

$22 a$<smiles>COc1ccccc1</smiles>

$22 a$<smiles>COc1ccccc1</smiles>

$22 a$<smiles>COc1ccc(C)cc1</smiles>

$22 f$<smiles>COc1ccc(C(C)C)cc1</smiles>

22g<smiles>COc1ccccc1</smiles>

$22 a$<smiles>COc1ccc(C)cc1</smiles>

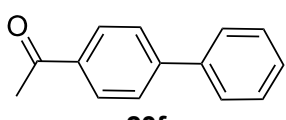

$23 f$<smiles>Nc1ccc(-c2ccccc2)cc1</smiles>

23g

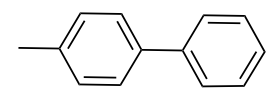

23h<smiles>COc1ccc(-c2ccccc2)c([N+](=O)[O-])c1</smiles>

23i<smiles>COc1ccc(-c2ccc(C)cc2)cc1</smiles>

23j
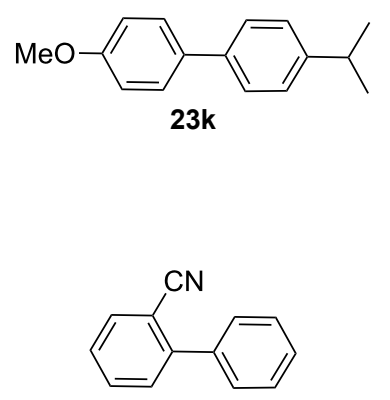

23I

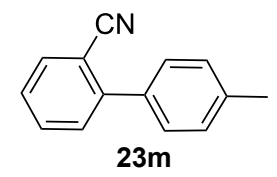

95

86

2

96

88

1.5

96

89

2

83

77

3

89

2
2

$22 f$

${ }^{a}$ Catalyst loading (0.5 mol \%), $\operatorname{ArX}(1.63 \mathrm{mmol}), \operatorname{ArB}(\mathrm{OH})_{2}(2.61 \mathrm{mmol}), \mathrm{H}_{2} \mathrm{O}(2 \mathrm{~mL}), \mathrm{KOH}(3.26 \mathrm{mmol}), 120^{\circ} \mathrm{C}, 2 \mathrm{~h}, \mathrm{TBAB}(0.5 \mathrm{equiv}$ relative to $\mathrm{ArX})$.

the study described in this article the coupling reaction is proposed to proceed via a $\mathrm{Pd}(\mathrm{II})$ to $\mathrm{Pd}(\mathrm{IV})$ mechanism. This suggests the effect of the chain length of the linker and the nature of the backbone on the catalytic activity of the SNS pincer Pd(II) complexes. In the future, efforts to fine tune the electronic and structural features of the thiophenyl and pyridinyl 


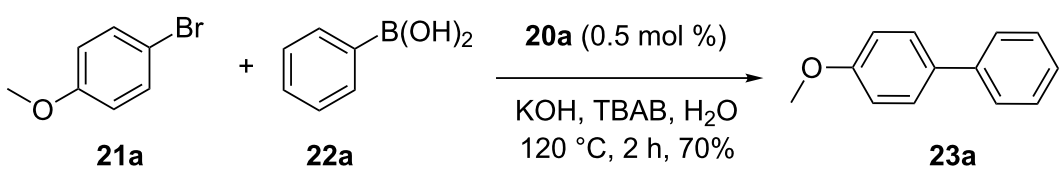

Scheme 4: Suzuki-Miyaura coupling reaction catalysed by the SN-bidentate complex 20a.

groups will be carried out in order to enable the catalysts to activate aryl chlorides, possessing electron-donating substituents, in the coupling reaction.

\section{Supporting Information}

\section{Supporting Information File 1}

Experimental part.

[https://www.beilstein-journals.org/bjoc/content/

supplementary/1860-5397-14-160-S1.pdf]

\section{Supporting Information File 2}

NMR spectra.

[https://www.beilstein-journals.org/bjoc/content/

supplementary/1860-5397-14-160-S2.pdf]

\section{Acknowledgements}

We thank the University of Johannesburg (UJ), the Research Centre for Synthesis and Catalysis of the Department of Chemistry at UJ, Sasol Ltd and the National Research Foundation (NRF) for funding. The use of UJ Spectrum's NMR facilities is also acknowledged. We would also like to thank Mr. Novisi Oklu for his help in solving of the crystal structure.

\section{ORCID ${ }^{\circledR}$ iDs}

Alphonse Fiebor - https://orcid.org/0000-0003-0836-0943 Banothile C. E. Makhubela - https://orcid.org/0000-0002-2292-7400 Henok H. Kinfe - https://orcid.org/0000-0002-4958-2836

\section{References}

1. Suzuki, A. Pure Appl. Chem. 1991, 63, 419-422. doi:10.1351/pac199163030419

2. Miyaura, N.; Suzuki, A. Chem. Rev. 1995, 95, 2457-2483. doi:10.1021/cr00039a007

3. Suzuki, A. J. Organomet. Chem. 1999, 576, 147-168. doi:10.1016/S0022-328X(98)01055-9

4. Chatterjee, A.; Ward, T. R. Catal. Lett. 2016, 146, 820-840. doi:10.1007/s10562-016-1707-8

5. Polshettiwar, V.; Decottignies, A.; Len, C.; Fihri, A. ChemSusChem 2010, 3, 502-522. doi:10.1002/cssc.200900221

6. Röhlich, C.; Wirth, A. S.; Köhler, K. Chem. - Eur. J. 2012, 18, 15485-15494. doi:10.1002/chem.201201266

7. Baxendale, I. R.; Griffiths-Jones, C. M.; Ley, S. V.; Tranmer, G. K. Chem. - Eur. J. 2006, 12, 4407-4416. doi:10.1002/chem.200501400
8. Yan, J.; Hu, W.; Zhou, W. Synth. Commun. 2006, 36, 2097-2102. doi:10.1080/00397910600636477

9. Cohen, A.; Crozet, M. D.; Rathelot, P.; Vanelle, P. Green Chem. 2009, 11, 1736-1742. doi:10.1039/b916123f

10. Dawood, K. M.; El-Deftar, M. M. ARKIVOC 2010, 319-330. doi:10.3998/ark.5550190.0011.930

11. Tairai, A.; Sarmah, C.; Das, P. Indian J. Chem. 2012, 51B, 843-848.

12. Shen, L.; Huang, S.; Nie, Y.; Lei, F. Molecules 2013, 18, 1602-1612. doi:10.3390/molecules18021602

13. Massaro, M.; Riela, S.; Lazzara, G.; Gruttadauria, M.; Milioto, S.; Noto, R. Appl. Organomet. Chem. 2014, 28, 234-238. doi:10.1002/aoc.3114

14. Hervé, G.; Len, C. Front. Chem. (Lausanne, Switz.) 2015, 3, No. 10. doi:10.3389/fchem.2015.00010

15. Li, Q. H.; Ding, Y.; Zhang, G.; Zhang, Z.; Mo, S. Curr. Org. Synth. 2017, 14, 462-476. doi:10.2174/1570179413666160624092044

16. Zhang, J.; Yang, F.; Ren, G.; Mak, T. C.; Song, M.; Wu, Y. Ultrason. Sonochem. 2008, 15, 115-118. doi:10.1016/j.ultsonch.2007.02.002

17. de Souza, A. L. F.; da Silva, L. C.; Oliveira, B. L.; Antunes, O. Tetrahedron Lett. 2008, 49, 3895-3898. doi:10.1016/j.tetlet.2008.04.061

18. Said, K.; Salem, R. B. Adv. Chem. Eng. Sci. 2016, 06, 111-123. doi:10.4236/aces.2016.62013

19. Leadbeater, N. E.; Marco, M. Org. Lett. 2002, 4, 2973-2976. doi:10.1021/ol0263907

20. Liu, L.; Zhang, Y.; Xin, B. J. Org. Chem. 2006, 71, 3994-3997. doi:10.1021/jo060122v

21. Liu, C.; Ni, Q.; Hu, P.; Qiu, J. Org. Biomol. Chem. 2011, 9, 1054-1060. doi:10.1039/c0ob00524j

22. Liang, Q.; Xing, P.; Huang, Z.; Dong, J.; Sharpless, K. B.; Li, X.; Jiang, B. Org. Lett. 2015, 17, 1942-1945. doi:10.1021/acs.orglett.5b00654

23. Massaro, M.; Riela, S.; Cavallaro, G.; Colletti, C. G.; Milioto, S.; Noto, R.; Parisi, F.; Lazzara, G. J. Mol. Catal. A: Chem. 2015, 408, 12-19. doi:10.1016/j.molcata.2015.07.008

24. Liu, C.; Li, X.; Wang, X.; Qiu, J. Turk. J. Chem. 2015, 39, 1208-1215. doi:10.3906/kim-1505-97

25. Hussain, I.; Capricho, J.; Yawer, M. A. Adv. Synth. Catal. 2016, 358, 3320-3349. doi:10.1002/adsc.201600354

26. DeVasher, R. B.; Moore, L. R.; Shaughnessy, K. H. J. Org. Chem. 2004, 69, 7919-7927. doi:10.1021/jo048910c

27. Zhou, J.; Guo, X.; Tu, C.; Li, X.; Sun, H. J. Organomet. Chem. 2009, 694, 697-702. doi:10.1016/j.jorganchem.2008.11.060

28. Garrido, R.; Hernández-Montes, P. S.; Gordillo, Á.; Gómez-Sal, P.; López-Mardomingo, C.; de Jesús, E. Organometallics 2015, 34 , 1855-1863. doi:10.1021/om501295b

29. Matsinha, L. C.; Mao, J.; Mapolie, S. F.; Smith, G. S. Eur. J. Inorg. Chem. 2015, 4088-4094. doi:10.1002/ejic.201500588 
30. Qiu, P.; Zhao, J. Y.; Shi, X.; Duan, X. H. New J. Chem. 2016, 40, 6568-6572. doi:10.1039/c6nj00377j

31.Sun, N.; Chen, M.; Jin, L.; Zhao, W.; Hu, B.; Shen, Z.; Hu, X. Beilstein J. Org. Chem. 2017, 13, 1735-1744. doi:10.3762/bjoc.13.168

32. Kumar, A.; Rao, G. K.; Kumar, S.; Singh, A. K. Organometallics 2014, 33, 2921-2943. doi:10.1021/om4007196

33. Kumar, A.; Rao, G. K.; Kumar, S.; Singh, A. K. Dalton Trans. 2013, 42, 5200-5223. doi:10.1039/c2dt32432f

34. Bai, S.-Q.; Hor, T. S. A. Chem. Commun. 2008, 3172-3174. doi:10.1039/b802043d

35. Kumar, S.; Rao, G. K.; Kumar, A.; Singh, M. P.; Singh, A. K. Dalton Trans. 2013, 42, 16939-16948. doi:10.1039/c3dt51658j

36. Soobramoney, L.; Bala, M. D.; Friedrich, H. B. Dalton Trans. 2014, 43, 15968-15978. doi:10.1039/C4DT01750A

37. Pioquinto-Mendoza, J. R.; Conelly-Espinosa, P.; Reyes-Martínez, R.; Toscano, R. A.; Germán-Acacio, J. M.; Avila-Sorrosa, A.; Baldovino-Pantaleón, O.; Morales-Morales, D. J. Organomet. Chem. 2015, 797, 153-158. doi:10.1016/j.jorganchem.2015.08.024

38. The crystallographic data is deposited at the Cambridge Crystallographic Data Centre and the CCDC \# of 17d is 1839866.

39. Sogukomerogullari, H. G.; Şen, F.; Dinçer, M.; Özdemir, N.; Sönmez, M. J. Mol. Struct. 2017, 1136, 271-280. doi:10.1016/j.molstruc.2017.02.015

40. Ocansey, E.; Darkwa, J.; Makhubela, B. C. E. RSC Adv. 2018, 8, 13826-13834. doi:10.1039/C8RA01430B

41. Peris, E.; Loch, J. A.; Mata, J.; Crabtree, R. H. Chem. Commun. 2001, 201-202. doi:10.1039/b008038I

42. Olsson, D.; Wendt, O. F. J. Organomet. Chem. 2009, 694, 3112-3115. doi:10.1016/j.jorganchem.2009.05.025

43. Bolliger, J.; Blacque, O.; Frech, C. Angew. Chem., Int. Ed. 2007, 46, 6514-6517. doi:10.1002/anie.200701804

44. Canty, A. J. Acc. Chem. Res. 1992, 25, 83-90. doi:10.1021/ar00014a005

45. Cundari, T. R.; Deng, J. J. Chem. Inf. Comput. Sci. 1999, 39, 376-381. doi:10.1021/ci980145d

46. Bosque, R.; Maseras, F. J. Comput. Chem. 2000, 21, 562-571. doi:10.1002/(SICI)1096-987X(200005)21:7<562::AID-JCC5>3.0.CO;20

47. Monteiro, A. L.; Davis, W. M. J. Braz. Chem. Soc. 2004, 15, 83-95. doi:10.1590/S0103-50532004000100014

48. Nicasio-Collazo, J.; Álvarez, E.; Alvarado-Monzón, J. C.; Andreu-de-Riquer, G.; Jimenez-Halla, J. O. C.;

De León-Rodríguez, L. M.; Merino, G.; Morales, U.; Serrano, O.;

López, J. A. Dalton Trans. 2011, 40, 12450-12453.

doi:10.1039/c1dt11451d

\section{License and Terms}

This is an Open Access article under the terms of the Creative Commons Attribution License (http://creativecommons.org/licenses/by/4.0). Please note that the reuse, redistribution and reproduction in particular requires that the authors and source are credited.

The license is subject to the Beilstein Journal of Organic Chemistry terms and conditions:

(https://www.beilstein-journals.org/bjoc)

The definitive version of this article is the electronic one which can be found at:

doi:10.3762/bjoc. 14.160 